\title{
Allogeneic morphogenetic protein vs. recombinant human bone morphogenetic protein-2 in lumbar interbody fusion procedures: a radiographic and economic analysis
}

Jeffrey S Roh ${ }^{1 *}$, Christopher A Yeung ${ }^{2}$, Justin S Field ${ }^{2}$ and R Trigg McClellan ${ }^{3}$

\begin{abstract}
Background: Since the introduction of rhBMP-2 (Infuse ${ }^{\oplus}$ ) in 2002, surgeons have had an alternative substitute to autograft and its related donor site morbidity. Recently, the prevalence of reported adverse events and complications related to the use of rhBMP-2 has raised many ethical and legal concerns for surgeons. Additionally, the cost and decreasing reimbursement landscape of rhBMP-2 use have required identification of a viable alternative. Osteo allogeneic morphogenetic protein (OsteoAMP®) is a commercially available allograft-derived growth factor rich in osteoinductive, angiogenic, and mitogenic proteins. This study compares the radiographic fusion outcomes between rhBMP-2 and OsteoAMP allogeneic morphogenetic protein in lumbar interbody fusion spine procedures.
\end{abstract}

Methods: Three hundred twenty-one (321) patients from three centers underwent a transforaminal lumbar interbody fusion (TLIF) or lateral lumbar interbody fusion (LLIF) procedure and were assessed by an independent radiologist for fusion and radiographically evident complications. The independent radiologist was blinded to the intervention, product, and surgeon information. Two hundred and twenty-six (226) patients received OsteoAMP with autologous local bone, while ninety-five (95) patients received Infuse with autologous local bone. Patients underwent radiographs ( $\mathrm{x}$-ray and/or $\mathrm{CT}$ ) at standard postoperative follow-up intervals of approximately $1,3,6,12$, and 18 months. Fusion was defined as radiographic evidence of bridging across endplates, or bridging from endplates to interspace disc plugs. Osteobiologic surgical supply costs were also analyzed to ascertain cost differences between OsteoAMP and rhBMP-2.

Results: OsteoAMP produced higher rates of fusion at 6,12 , and 18 months $(p \leq 0.01)$. The time required for OsteoAMP to achieve fusion was approximately $40 \%$ less than rhBMP-2 with approximately $70 \%$ fewer complications. Osteobiologic supply costs were $80.5 \%$ lower for OsteoAMP patients (73.7\% lower per level) than for rhBMP-2.

Conclusions: Results of this study indicate that OsteoAMP is a viable alternative to rhBMP-2 both clinically and economically when used in TLIF and LLIF spine procedures.

Keywords: rhBMP-2, Spine, Bone graft, Allograft, Protein, Interbody, Fusion, OsteoAMP

\footnotetext{
* Correspondence: jeffreyrohmd@gmail.com

'Orthopedics International, 12333 NE 130th Lane \#400, Kirkland, WA 98034,

USA

Full list of author information is available at the end of the article
}

\section{Biomed Central}

(c) 2013 Roh et al.; licensee BioMed Central Ltd. This is an Open Access article distributed under the terms of the Creative Commons Attribution License (http://creativecommons.org/licenses/by/2.0), which permits unrestricted use, distribution, and reproduction in any medium, provided the original work is properly cited. The Creative Commons Public Domain Dedication waiver (http://creativecommons.org/publicdomain/zero/1.0/) applies to the data made available in this article, unless otherwise stated. 


\section{Background}

Autograft, harvested from the iliac crest, has long been considered the 'gold standard' for spinal fusion. Though the use of autograft is well studied, limited tissue availability, donor site morbidity, and increased surgical time are also well understood [1]. In 1965, Dr. Marshal Urist discovered trace amounts of bone morphogenetic proteins (BMPs) naturally found within the bone matrix. Since this discovery, a wide range of allogeneic bone grafts has become available as a substitute or extender to autograft [2], yet with limited success. The goal of these allogeneic bone grafts was to offer the greatest amount of BMP available within the tissue, but these bone graft products are constrained by the small amount of BMPs found within the actual collagen matrix [3].

In 2002, the FDA approved the use of a recombinant human bone morphogenetic protein-2 (Infuse, Medtronic Inc., Fridley, MN, USA) for single-level anterior lumbar interbody fusion (ALIF) spine surgery. The initial success of rhBMP-2 with interbody fusion soon led to off-label use, beyond the initial FDA indication [4]. Unfortunately, many adverse events have been reported stemming from its use, including retrograde ejaculation, dysphagia, ectopic bone formation and potentially cancer, leading clinicians to question the clinical benefit versus patient safety [4-7]. In 2013, the Yale University Open Data Access (YODA) Project determined that there was no increased incidence of retrograde ejaculation, though the potential increase in cancer was higher in Infuse patients. The YODA study indicated that the increased cancer incidence with rhBMP-2 was $1.9 \%-3 \%$ [8].

The discovery of a new allogeneic tissue processing technique has provided a way to access BMPs and other growth factors that are naturally found within bone marrow cells. OsteoAMP (Advanced Biologics Carlsbad, CA, USA) is an allogeneic morphogenetic protein that undergoes a novel tissue processing technique, utilizing angiogenic, mitogenic and osteoinductive growth factors such as BMP-2, BMP-7, TGF- $\beta 1$, aFGF, VEGF, and ANG1, within bone marrow cells [9-11] and naturally binds them back to the bone graft being processed. This array of growth factors, beneficial to bone growth, could offer an alternative to rhBMP-2 and other current bone graft substitutes on the market today.

The objective of this study was to compare OsteoAMP allogeneic morphogenetic protein to rhBMP-2 by examining the radiographic evidence of spinal fusion at various time points in patients who have undergone lumbar interbody fusion and to also examine the costs associated with the use of these products.

\section{Methods}

A dual-arm radiographic analysis was conducted at three clinical sites to evaluate the fusion success rate of a commercially available allogeneic morphogenetic protein
Table 1 Pathology breakdown

\begin{tabular}{lcc}
\hline Pathology breakdown & $\begin{array}{c}\text { OsteoAMP (\%) } \\
(\boldsymbol{n}=\mathbf{2 2 6})\end{array}$ & $\begin{array}{c}\text { rhBMP-2 (\%) } \\
(\boldsymbol{n}=\mathbf{9 5})\end{array}$ \\
\hline DDD & 21.7 & 26.3 \\
Herniated disc & 25.7 & 2.1 \\
Pseudarthrosis/nonunion/hardware & 5.3 & 6.3 \\
failure/revision & & 1.1 \\
Post laminectomy/fusion syndrome & 21.2 & 1.1 \\
Radiculitis/radiculopathy & 51.3 & 10.5 \\
Scoliosis & 11.1 & 0.0 \\
Spondylosis & 8.8 & 75.8 \\
Spondylolisthesis & 74.8 & 17.9 \\
Stenosis & 58.0 & \\
\hline Patients presen
\end{tabular}

Patients presented with multiple pathologies; thus, the percentage will not equal 100.

(OsteoAMP) and rhBMP-2 (Infuse) in lumbar spine surgery. Radiologic review and evaluation were conducted by a blinded independent radiologist for interbody fusion. The indications for surgery were symptomatic patients diagnosed with degenerative disc disease (DDD), stenosis, and/or spondylolisthesis (Table 1). Surgical supply costs for the osteobiologics used were also analyzed to present an overall value analysis between the two arms.

\section{Patient demographics}

Three hundred twenty-one consecutive patients over the course of 5 years underwent transforaminal lumbar interbody fusion (TLIF) or lateral lumbar interbody fusion (LLIF) between T4 and S1 (522 operative levels/501 interbody fusion levels). A group of 95 patients with a mean age of 54.3 were treated with rhBMP-2 with an average of 1.63 levels per surgery. A group of 226 patients with a mean age

Table 2 Patient baseline characteristics

\begin{tabular}{lcc}
\hline Characteristic & $\begin{array}{c}\text { OsteoAMP } \\
(\boldsymbol{n}=\mathbf{2 2 6})\end{array}$ & $\begin{array}{c}\text { rhBMP-2 } \\
(\boldsymbol{n}=\mathbf{9 5})\end{array}$ \\
\hline Age, mean \pm SD & $60.0 \pm 13.0$ & $54.3 \pm 10.9$ \\
Female, $n$ (\%) & $131(58.0)$ & $56(58.9)$ \\
Average levels/case & 1.62 & 1.63 \\
Operative levels, $n$ (\%) & & $72(75.8)$ \\
One & $147(65.0)$ & $14(14.7)$ \\
Two & $58(25.7)$ & $1(1.1)$ \\
Three & $9(4.0)$ & $2(2.1)$ \\
Four & $4(1.8)$ & $1(1.1)$ \\
Five & $3(1.3)$ & $0(0.0)$ \\
Six & $0(0.0)$ & $3(3.2)$ \\
Seven & $3(1.3)$ & $1(1.1)$ \\
Eight & $1(0.4)$ & $1(1.1)$ \\
Twelve & $1(0.4)$ & \\
\hline
\end{tabular}


Table 3 Radiologic breakdown for fusion

\begin{tabular}{lcc}
\hline Radiologic breakdown & OsteoAMP $(\boldsymbol{n}=\mathbf{2 2 6})$ & rhBMP-2 $(\boldsymbol{n}=\mathbf{9 5})$ \\
\hline Static X-ray & 161 & 38 \\
Computer tomography & 65 & 57 \\
\hline
\end{tabular}

of 60.0 were treated with OsteoAMP with an average of 1.62 levels per surgery (Table 2). On average, patients in the OsteoAMP arm were $10.5 \%$ older than the patients in the rhBMP-2 cohort.

\section{Materials}

Both arms utilized morselized local bone from the surgical site in combination with the osteobiologic. In the first arm, OsteoAMP was used in conjunction with the centers' preferred spinal spacer and fixation system. OsteoAMP was prepared for use per the instructions by the manufacturer (Advanced Biologics). In 58.4\% of the OsteoAMP with local bone cases, bone marrow aspirate (BMA) was also added. In the second arm, rhBMP-2 was obtained and loaded onto the absorbable collagen sponge (ACS) as directed by the instructions for use. The rhBMP-2 was then combined with local autologous bone and packed into an interbody device. On average, approximately $3.07 \mathrm{mg}$ of rhBMP-2 was used inside the interbody device per level.

\section{Analysis}

Patients underwent radiographs ( $\mathrm{x}$-ray and/or CT) at standard postoperative follow-up time points, which were generally at $6,13,26,52$, and 72 weeks postsurgical procedure. In both arms, the majority of fusion assessments at each time point were made using static radiographs (Table 3). Although CT is widely accepted as the standard for noninvasive assessment of spinal fusion, the increased radiation exposure and limited equipment availability make it impractical to subject patients to CT at each visit [12].
When evaluated appropriately, literature has shown x-rays to have similar accuracy when assessing fusion [13].

An independent radiologist made fusion assessments based on these studies and was blinded to intervention, product, and surgeon information. Fusion was defined as any radiographic evidence of bridging across endplates, or bridging from endplates to interspace disc plugs (Figure 1). Any radiodensity that obliterates or blurs the lucency between endplates and plugs that was seen on the postoperative films was considered an evidence of fusion. Fusion success rate of each patient was then analyzed for both study arms at each time point. The time frame between surgical intervention and positive fusion assessment was calculated and radiologically evident complications of osteolysis or ectopic bone formation were reported. Osteobiologic surgical supply costs were determined by reporting cost of the implant utilized inside the spinal spacer or interbody device. If BMA was utilized, the cost of the jamshidi needle was included in the overall cost. In addition, a secondary analysis was conducted within the first arm to identify any correlation between the use of BMA and fusion success.

\section{Results}

\section{Fusion success rate}

The series of radiographs from each patient were evaluated comparing postoperative $\mathrm{x}$-rays and each consecutive time point for evidence of fusion to ensure that the opacity of the biologic or local bone was not a factor in the fusion assessment. The comparison of both arms demonstrated a statistically significant difference in the increase of fusion over each consecutive follow-up time point. Of the 226 patients receiving OsteoAMP, the radiographic fusion analysis indicated that there was fusion in $59.7 \%$ at 6 months, $93.3 \%$ at 12 months, and $98.9 \%$ at 18 months. Of the 95 patients receiving rhBMP-2, the analysis indicated that there was fusion in $39.3 \%$ at 6 months, $83.5 \%$ at 12 months, and $90.1 \%$ at 18 months (Table 4). The results indicated a

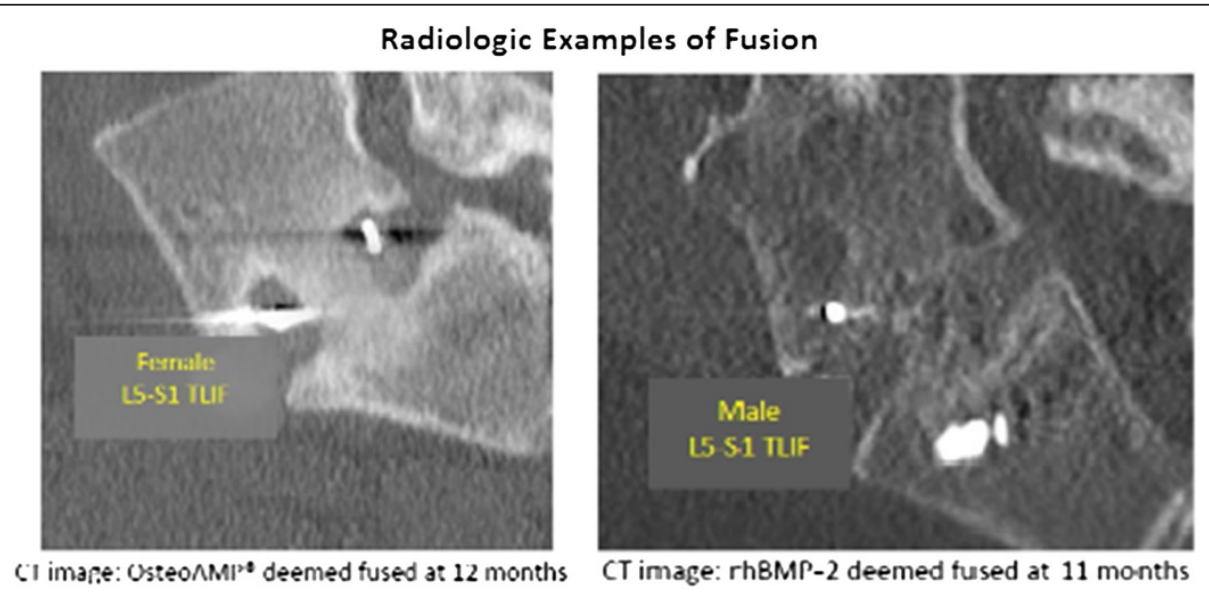

Figure 1 Radiologic examples of fusion. 
Table 4 Fusion success at each time point

\begin{tabular}{lcc}
\hline $\begin{array}{l}\text { Time point fusion } \\
\text { (months) }\end{array}$ & $\begin{array}{c}\text { OsteoAMP (\%) } \\
(\boldsymbol{n}=\mathbf{2 2 6})\end{array}$ & $\begin{array}{c}\text { rhBMP-2 (\%) } \\
(\boldsymbol{n}=\mathbf{9 5})\end{array}$ \\
\hline 3 & 18.6 & 10.5 \\
6 & 59.7 & 39.3 \\
12 & 93.3 & 83.5 \\
18 & 98.9 & 90.1 \\
\hline
\end{tabular}

higher percentage of patients fused in the OsteoAMP group at all time points $(p \leq 0.01)$ (Figure 2). Total time for fusion for OsteoAMP was approximately $40 \%$ shorter than that of rhBMP-2 (207.9 and 333.9 days, respectively).

\section{BMA analysis}

Of the 132 patients receiving OsteoAMP with BMA, the radiographic fusion analysis determined that $61.9 \%$ of patients were fused at 6 months, $93.9 \%$ at 12 months, and $99.1 \%$ at 18 months. Of the 94 patients receiving OsteoAMP without BMA, the analysis indicated that $56.7 \%$ fused at 6 months, $92.6 \%$ at 12 months and $98.7 \%$ at 18 months (Table 5). The difference between groups was not statistically significant ( $p=0.44$ at 6 months, $p>$ 0.72 at 12 and 18 months) (Figure 3).

\section{Osteobiologic surgical supply cost analysis}

The 95 patient rhBMP-2 arm utilized an average of $2.05 \mathrm{cc}$ (3.07 mg rhBMP-2) inside the interbody device per level. The supply costs associated with rhBMP-2 was US\$2,523.52 per level. The OsteoAMP arm utilized an average of $2.5 \mathrm{cc}$ per level inside the spinal spacer. The supply costs associated with OsteoAMP was US\$649.20 per level. The addition of a jamshidi needle used for BMA collection brought the OsteoAMP weighted cost per level to US\$663.61. The OsteoAMP arm was $80.5 \%$ less expensive per patient (73.7\% per level) than the rhBMP-2 arm.

\section{Complications}

The observation of complications was noted by reviewing $\mathrm{x}$-rays, CT reports, general radiological assessment, and surgeon's notes. The rhBMP-2 arm seemed to have greater radiologically evident adverse events compared to the OsteoAMP arm. Radiologic evidence of ectopic bone formation was found in $24.2 \%$ of the rhBMP-2 cases compared to $5.3 \%$ in patients receiving OsteoAMP $(p<0.01)$. There was also greater radiologic evidence of osteolysis, subsidence, or endplate irregularity in the patients receiving rhBMP-2 (10.5\%) versus OsteoAMP (5.3\%) $(p=0.06)$ (Figure 4). It should be noted that the complication observations in both study arms could be underreported due to the use of other methods besides CT (standard method) to assess complications.

\section{Discussion}

Long-term success following lumbar fusion procedures is predicated on the integrity of the fused interbody segments, yet the literature reports that nonunions occur in $10 \%$ to $20 \%$ of patients with single-level fusions [14-17]. Autograft from the iliac crest has been used successfully; however, morbidity, limited supply, and additional operating time associated with autograft harvest have led surgeons to consider alternatives.

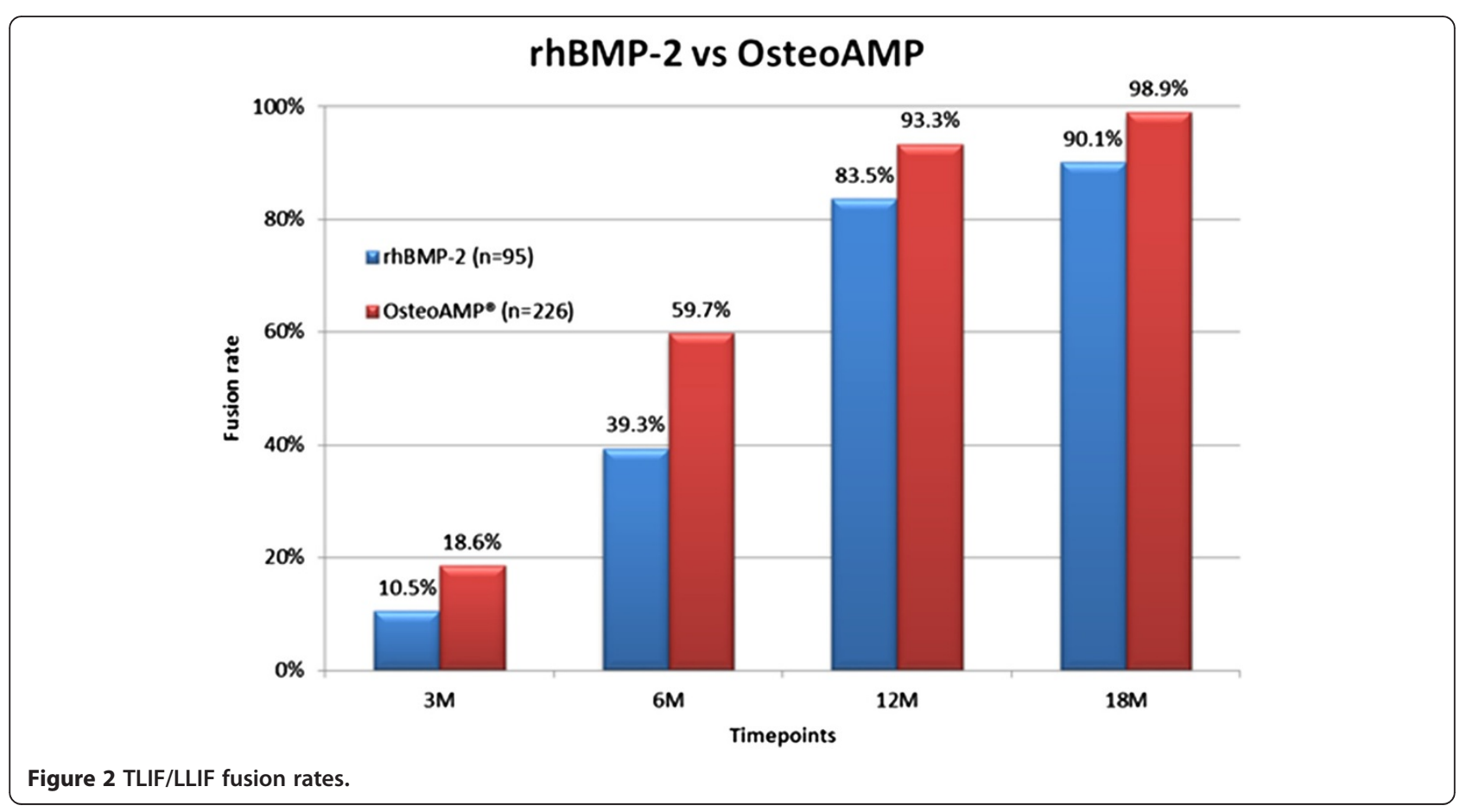


Table 5 Fusion success at each time point (BMA)

\begin{tabular}{lcc}
\hline $\begin{array}{l}\text { Time point } \\
\text { (months) }\end{array}$ & $\begin{array}{c}\text { OsteoAMP }{ }^{\oplus} \text { with BMA } \\
\text { (\%) }(\boldsymbol{n}=\mathbf{1 3 2})\end{array}$ & $\begin{array}{c}\text { OsteoAMP }{ }^{\oplus} \text { without BMA } \\
\text { (\%) }(\boldsymbol{n}=\mathbf{9 4})\end{array}$ \\
\hline 3 & 18.9 & 18.1 \\
6 & 61.9 & 56.7 \\
12 & 94.7 & 92.6 \\
18 & 99.1 & 98.7 \\
\hline
\end{tabular}

The evolution of bone graft materials, advanced implant designs, and less invasive surgical techniques has greatly improved clinical outcomes [18-20]. There are many bone graft alternatives today, each with advantages and disadvantages. These bone graft alternatives will become more highly refined, as our knowledge continues to improve regarding the biology and mechanics of spinal fusion $[14,21]$.

The introduction of rhBMP-2 in 2002 provided access to large quantities of BMP that is only available in trace amounts in demineralized bone or autograft [22]. Successful fusion results of rhBMP-2 when used in anterior lumbar interbody fusions are well documented [23,24]. As surgeons began to incorporate more minimally invasive techniques, the off-label use of rhBMP-2 has increased. In addition, the use in cervical procedures has led to serious complications [25]. Since then, there have been many attempts to facilitate bone healing and new bone growth to the same degree as with rhBMP-2. More recently, the use of stem cells, harvested from cadavers and frozen prior to surgery, has attempted to deliver viable cells directly to the surgical site [26]. While there are some reports of

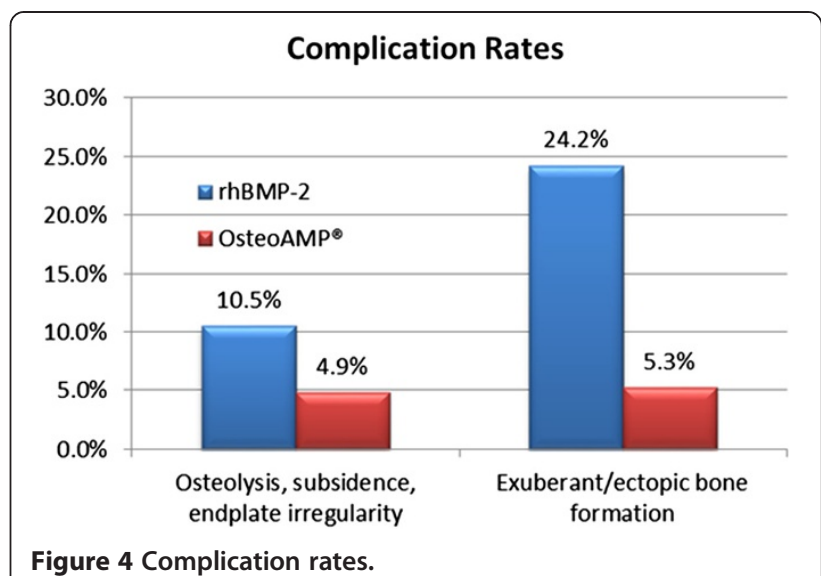

successful outcomes in the literature [27], the question still remains regarding the efficacy of such products [28].

In 2009, OsteoAMP was made commercially available. Utilizing a novel tissue processing technique, the naturally occurring growth factors and BMPs from bone marrow cells are harvested and naturally bound to the cadaver bone providing a product with angiogenic, mitogenic, and osteoinductive properties.

In a retrospective study from three centers over a 5-year period, radiographic fusion (x-ray and $\mathrm{CT}$ ) was compared between OsteoAMP and rhBMP-2. The rate of fusion assessed by an independent radiologist was higher in the OsteoAMP group at all intervals $(p \leq 0.01)$. Although adverse events were only determined by radiological review in this study, OsteoAMP had dramatically fewer complications than rhBMP-2. These results seem to support the

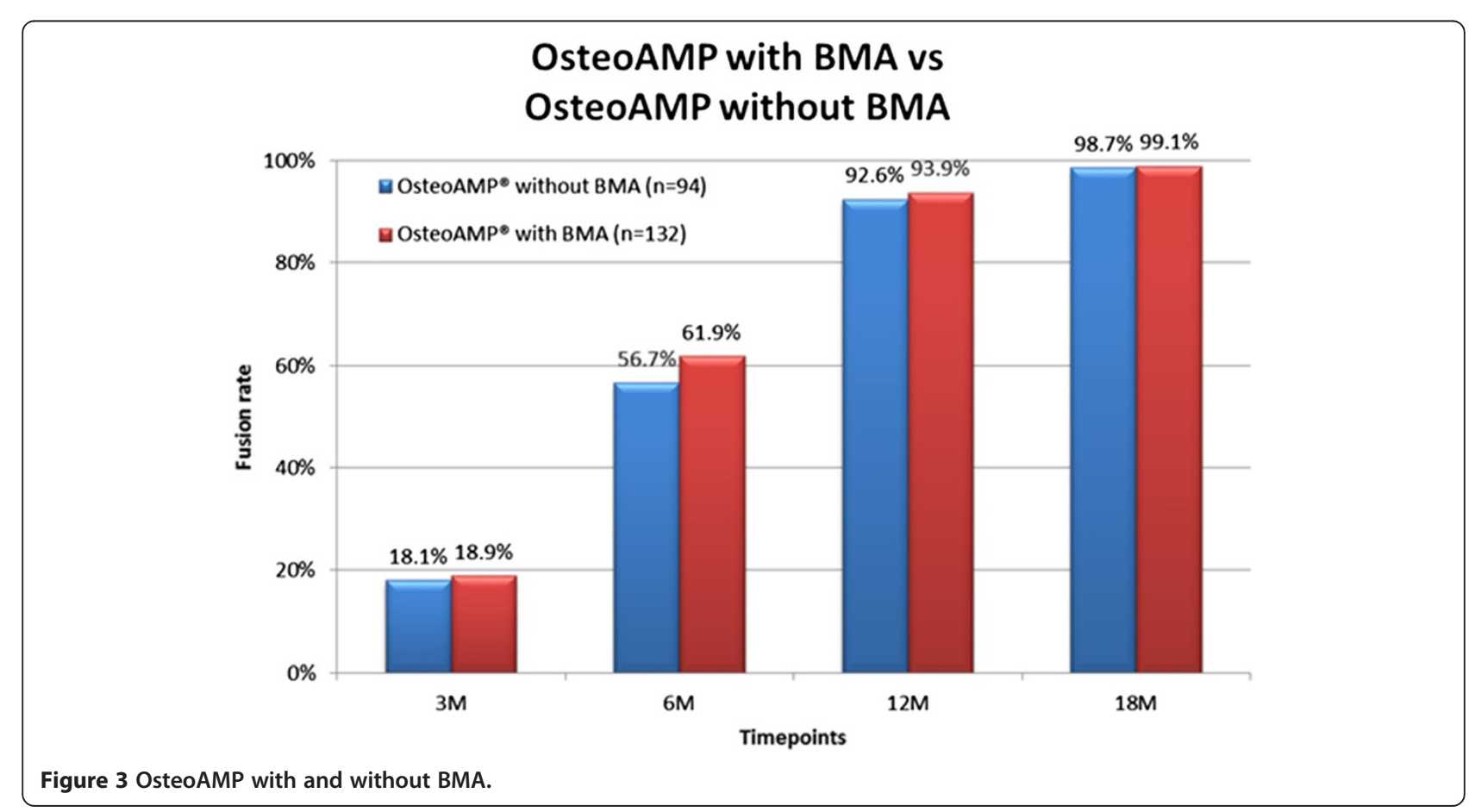


benefits of having an array of growth factors that are found in OsteoAMP. Bone remodeling involves factors, such as insulin-like growth factors (IGFs), BMPs, and vascular endothelial growth factor (VEGF) to not only stimulate cell recruitment and proliferation but also encourage vascularization $[29,30]$. OsteoAMP is processed so that these growth factors are made bioavailable.

Since standard practice at all three centers included the use of BMA, data was analyzed to identify the efficacy of BMA. When comparing the fusion results within the OsteoAMP patient population with and without BMA, data suggests little difference in fusion success with or without BMA.

Preparation of OsteoAMP is similar to other bone substitutes. The product is often reconstituted with blood or BMA to help with the handling characteristics prior to use. Unlike rhBMP-2, there is no time required for growth factor binding. However, aspiration of bone marrow will be dependent on surgical technique and could be difficult to mix with the graft if allowed to congeal in the aspiration syringe.

The inherent risks with the use of allograft tissue and bovine collagen have been discussed in literature for many years. Allogeneic materials are widely used in orthopedics; according to the Centers for Disease Control and Prevention, there have been no reports of disease transmission during the 30-year history of using freeze-dried bone allografts. However, there have been reports of disease transmission in nonsterile fresh-frozen bone allografts [31], and literature reports that $3 \%$ to $5 \%$ of the population is hypersensitive to bovine collagen [32,33]. The established exclusionary criteria combined with recommended processing procedures established by the American Academy of Tissue Banking have ensured that freeze-dried bone allografts are safe for human implantation [34,35].

There were a number of potential limitations in this study. Each center used different instrumentation and fixation devices, which may influence some of the results. The study did not evaluate the clinical outcomes, and follow-up CTs as well as $\mathrm{x}$-rays were used to assess fusion over each time point. In addition, the three surgeons have unique surgical techniques that may have contributed to some variability within the results.

\section{Conclusions}

The results of this study indicated a higher percentage of patients fused in the OsteoAMP group at all time points $(p \leq 0.01)$ (Figure 2). Furthermore, the OsteoAMP arm was shown to be $80.5 \%$ less expensive per patient $(73.7 \%$ per level) than the rhBMP-2 arm. The economic analysis and superior fusion rate results in this study support OsteoAMP as a cost-effective and viable alternative to rhBMP-2. Multicenter randomized controlled studies will be necessary to confirm the efficacy and cost-effectiveness of OsteoAMP as a superior osteobiologic.

\section{Consent}

When necessary, written informed consent was obtained from the patient for the publication of this report and any accompanying images.

\section{Competing interests}

TM is an unpaid consultant for Advanced Biologics. Authors JR, CY, and JF are unpaid consultants for Advanced Biologics and hold shares in the company.

\section{Authors' contributions}

$\mathrm{JR}, \mathrm{CY}$, and JF contributed equally to the manuscript and provided the clinical data necessary for analysis. TM participated in the manuscript and the statistical data analysis. All authors read and approved the final manuscript.

\section{Acknowledgements}

The authors would like to thank Azar P. Dagher, M.D., ABR, CAQ Neuroradiology for the radiologic analysis required for this study.

\section{Author details}

${ }^{1}$ Orthopedics International, 12333 NE 130th Lane \#400, Kirkland, WA 98034, USA. 'Desert Institute for Spine Care, 1635 E Myrtle Ave, Phoenix, AZ 85020, USA. ${ }^{3}$ Orthopaedic Trauma Institute, San Francisco General Hospital, UCSF, 2550 23rd Street, San Francisco, CA 94110, USA.

Received: 6 September 2013 Accepted: 12 December 2013

Published: 28 December 2013

\section{References}

1. Agarwal R, Williams K, Umscheid CA, Welch WC: Osteoinductive bone graft substitutes for lumbar fusion: a systematic review. J Neurosurg Spine 2009, 11:729-740.

2. Urist MR: Bone: formation by autoinduction. Science 1965, 150:893-899. doi:10.1126/science.150.3698.893.

3. Valdes MA, Thakur NA, Namdari S, Ciombor DM, Palumbo M: Recombinant bone morphogenic protein-2 in orthopaedic surgery: a review. Arch Orthop Trauma Surg 2009, 129:1651-1657.

4. Fu R, Selph S, McDonagh M, Peterson K, Tiwari A, Chou R, Helfand M: Effectiveness and harms of recombinant human bone morphogenetic protein-2 in spine fusion: a systematic review and meta-analysis. Ann Intern Med 2013, 158:12.

5. Carragee EJ, Mitsunaga KA, Hurwitz EL, Scuderi GJ: Retrograde ejaculation after anterior lumbar interbody fusion using rhBMP-2: a cohort controlled study. Spine J 2012, 12(10):881-890. doi: 10.1016/j.spinee.2012.09.040.

6. Carragee EJ, Hurwitz EL, Weiner BK: A critical review of recombinant human bone morphogenetic protein-2 trials in spinal surgery: emerging safety concerns and lessons learned. Spine J 2011, 11(6):471-491. doi:10.1016/j.spinee.2011.04.023.

7. U.S. Food and Drug Administration: Recombinant human bone morphogenetic protein in cervical spine fusion. Silver Spring, MD: U.S. Food and Drug Administration; 2008 [www.fda.gov/Safety/MedWatch/ SafetyInformation/SafetyAlertsforHumanMedicalProducts/ucm079019.htm].

8. Fu R, Selph S, McDonagh M, Peterson K, Tiwari A, Chou R, Helfand M: Effectiveness and harms of recombinant human bone morphogenetic protein-2 in spine fusion. Ann Intern Med 2013, 158:12.

9. Kaigler D, Krebsbach PH, Polverini PJ, Mooney DJ: Role of vascular endothelial growth factor in bone marrow stromal cell modulation of endothelial cells. Tissue Eng 2011, 9:1.

10. Khan SN, Cammisa FP Jr, Sandhu HS, Diwan AD, Girardi FP, Lane JM: The biology of bone grafting. J Am Acad Orthop Surg 2005, 13:1.

11. Brunner G, Nguyen H, Gabrilove J, Rifkin DB, Wilson EL: Basic fibroblast growth factor expression in human bone marrow and peripheral blood cells. Blood J 1993, 81:631-638.

12. Selby MD, Clark SR, Hall DJ, Freeman BJ: Radiologic assessment of spinal fusion. J Am Acad Orthop Surg 2012, 20(11):694-703. doi:10.5435/JAAOS-20-11-694.

13. Fogel GR, Toohey JS, Neidre A, Brantigan JW: Fusion assessment of posterior lumbar interbody fusion using radiolucent cages: $x$-ray films 
and helical computed tomography scans compared with surgical exploration of fusion. Spine J 2008, 8(4):570-577.

14. Boden SD: Overview of the biology of lumbar spine fusion and principles for selecting a bone graft substitute. Spine 2002 27(16 Suppl 1):S26-S31.

15. DePalma AF, Rothman RH: The nature of pseudarthrosis. Clin Orthop 1968, 59:113-118.

16. Steinmann JC, Herkowitz HN: Pseudarthrosis of the spine. Clin Orthop 1992, 284:80-90

17. Fischgrund JS, Mackay M, Herkowitz HN, Brower R, Montgomery DM, Kurz LT: 1997 Volvo Award winner in clinical studies. Degenerative lumbar spondylolisthesis with spinal stenosis: a prospective, randomized study comparing decompressive laminectomy and arthrodesis with and without spinal instrumentation. Spine 1997, 22:2807-2812.

18. Glassman SD, Dimar JR, Carreon LY, Campbell MJ, Puno RM, Johnson JR: Initial fusion rates with recombinant human bone morphogenetic protein-2/compression resistant matrix and a hydroxyapatite and tricalcium phosphate/collagen carrier in posterolateral spinal fusion. Spine 2005, 30:1694-1698.

19. Bridwell KH, Sedgewick TA, O'Brien MF, Lenke LG, Baldus C: The role of fusion and instrumentation in the treatment of degenerative spondylolisthesis with spinal stenosis. J Spinal Disord 1993, 6:461-472.

20. Rodríguez-Vela J, Lobo-Escolar A, Joven E, Muñoz-Marín J, Herrera A, Velilla J: Clinical outcomes of minimally invasive versus open approach for one-level transforaminal lumbar interbody fusion at the 3- to 4-year follow-up. Eur Spine J 2013, 22:2857-2863.

21. Boden SD, Schimandle JH: Biologic enhancement of spinal fusion. Spine 1995, 20:113S-123S.

22. Dimar JR II, Glassman SD, Burkus JK, Pryor PW, Hardacker JW, Carreon LY: Clinical and radiographic analysis of an optimized rhBMP-2 formulation as an autograft replacement in posterolateral lumbar spine arthrodesis. J Bone Joint Surg Am 2009, 91:1377-1386.

23. Burkus JK, Gornet MF, Dickman CA, Zdeblick TA: Anterior lumbar interbody fusion using rhBMP-2 with tapered interbody cages. J Spinal Disord Tech 2002, 15(5):337-349.

24. Boden SD, Zdeblick TA, Sandhu HS, Heim SE: The use of rhBMP-2 in interbody fusion cages. Definitive evidence of osteoinduction in humans: a preliminary report. Spine 2000, 25(3):376-381.

25. Dorward IG, Buchowski JM, Stoker GE, Zebala LP: Posterior cervical fusion with recombinant human bone morphogenetic protein-2: complications and fusion rate at minimum two-year follow-up. J Spinal Disord Tech 2013. in press.

26. Neman J, Duenas V, Kowolik CM, Hambrecht AC, Chen MY, Jandial R: Lineage mapping and characterization of the native progenitor population in cellular allograft. Spine J 2013, 13(2):162-174.

27. Kerr EJ 3rd, Jawahar A, Wooten T, Kay S, Cavanaugh DA, Nunley PD: The use of osteo-conductive stem-cells allograft in lumbar interbody fusion procedures: an alternative to recombinant human bone morphogenetic protein. J Surg Orthop Adv 2011, 20(3):193-197.

28. Thompson N, et al: Osteoinductivity and osteoconductivity comparison of commonly used granule products. In Proceedings of the 7th Symposium on Biologic Scaffolds for Regenerative Medicine: April 26-28 2012. Napa Valley.

29. Hadjidakis DJ, Androulakis II: Bone remodeling. Ann N Y Acad Sci 2006, 1092:385-396.

30. Clarkin CE, Gerstenfeld LC: VEGF and bone cell signalling: an essential vessel for communication? Cell Biochem Funct 2013, 31(1):1-11. doi:10.1002/cbf.2911.

31. Centers for Disease Control and Prevention: Frequently asked questions. 2013 [http://www.cdc.gov/oralhealth/infectioncontrol/faq/allografts.htm].

32. Shoshani D, Markovitz E, Cohen Y, Heremans A, Goldlust A: Skin test hypersensitivity study of a cross-linked, porcine collagen implant for aesthetic surgery. Dermatol Surg 2007, 33(Suppl 2):S152-8.

33. Keefe J, Wauk L, Chu S, DeLustro F: Clinical use of injectable bovine collagen: a decade of experience. Clin Mater 1992, 9(3-4):155-62.
34. Buck BE, Malinin T, Brown MD: Bone transplantation and human immunodeficiency virus. Clin Orthop 1994, 303:8-17.

35. Bethesda MD, Simmonds RJ, Holmberg SD, Hurwitz RL, Coleman TR, Bottenfield S, Conley L, Kohlenberg SH, Castro KG, Dahan BA, Schable CA Rayfield MA, Rogers MF: Transmission of human immunodeficiency virus type 1 from a seronegative organ and tissue donor. N Engl J Med 1992, 326:726-732.

doi:10.1186/1749-799X-8-49

Cite this article as: Roh et al: Allogeneic morphogenetic protein vs. recombinant human bone morphogenetic protein-2 in lumbar interbody fusion procedures: a radiographic and economic analysis. Journal of Orthopaedic Surgery and Research 2013 8:49.

\section{Submit your next manuscript to BioMed Central and take full advantage of:}

- Convenient online submission

- Thorough peer review

- No space constraints or color figure charges

- Immediate publication on acceptance

- Inclusion in PubMed, CAS, Scopus and Google Scholar

- Research which is freely available for redistribution

Submit your manuscript at www.biomedcentral.com/submit
( Biomed Central 